\title{
Changing Epidemiology of Dengue
}

Dengue fever (DF) and its severe form, the dengue haemorrhagic fever (DHF), is a re emerging arboviral disease of great public health importance, and it has spread to all tropical and sub tropical countries in the world. Currently, an estimated 2.5 billion people in more than 100 countries are at risk. Globally, every year, an estimated 50 million dengue infections occur; half a million DHF cases require hospitalization with over 20000 deaths. ${ }^{1}$

Most countries in South East Asia bear a high burden of DF/DHF and experience frequent and cyclical epidemics. ${ }^{2}$ Also, the epidemiology of dengue in South East Asia is undergoing a change in the human host, the dengue virus and the vector bionomics. Shift in affected age groups, sex differences and expansion to rural areas are evident, while the virulence and genotype of the virus determine the severity and time interval between sequential infections.

The Aedes mosquito, a potent and adaptive vector, has evolved in longevity and survival, affected by seasonality and climate variability, socio cultural and economic factors of human habitation and development.

Dengue is caused by viruses belonging to genus Flavivirus (family Flaviviridae) with four known serotypes: DENV 1 through DENV. ${ }^{4}$ Infection with one serotype confers life long immunity to that serotype and a few months cross immunity to other serotypes. Sequential infection of two serotypes leads to more severe type of disease (e.g. DHF). All serotypes/genotypes are now circulating globally and maintaining hyperendemicity. 3,4

Aedes aegypti is the primary vector and establishes its habitat between latitude $35^{\circ} \mathrm{N}$ and $35^{\circ} \mathrm{S}$. This mosquito lives in proximity to human habitations in urban areas and breeds mostly in man made containers. This vector is a day time feeder, and its peak biting periods are early in the morning and before dusk. Female Ae. aegypti bites multiple people during each feeding period. Ae albopictus is considered a secondary vector, with characteristics of being highly adaptive, as it can survive in cooler climates and spread. Both species are sensitive to environmental conditions such as temperature, precipitation and humidity.

\section{Shift in affected age group}

In South East Asian countries, where all the serotypes (DENV 1-4) are circulating, DF is typically acknowledged to be a disease of early childhood, while clinical DF in adults is rare. DHF/DSS in these areas occurs mostly in children aged 2-15 years. Older and many of the younger inhabitants are usually immune and escape DHF, as they have acquired immunity against primary infection5. However, there is an evidence of increase of dengue incidence in older age groups, and this age shift has been reported in Singapore, Indonesia, Bangladesh and Thailand6. In Thailand, cases of DHF/DSS in small infants as young as 1-2 months and in adults have been reported with increasing frequency.

In first DHF outbreak in Bangladesh, the age group of 1833 years were the most affected. ${ }^{7}$

In India, a legendary film maker died of DHF with multi organ failure at the age of 80 years (Media Reports 21 October 2012) and older age group was significantly affected in the last major outbreaks in Delhi, India8

\section{Sex differences}

There are many studies from South East Asia region that suggest higher ratio of males than females in DF/DHF hospitalized cases (India, Bangladesh, Singapore and Malaysia), and only few studies suggest no difference in sexes. Studies in Malaysia by Kabra et al., ${ }^{9}$ and in India by Shekhar et al. ${ }^{10}$ reported a higher rate of mortalities among females than males, suggesting different pathogenesis processes or immune response.

\section{Changes in the dengue virus}

Virulence of the circulating virus is hypothesized to play a role in disease severity, and small genotypic changes in dengue viruses could lead to DHF emergence, as reported from a Sri Lankan study. ${ }^{11}$

\section{Rural spread}

DF/DHF has been believed to be a primarily urban disease as the vectors are well adapted to human habitation. However, dengue has spread into rural areas from where it had not been reported before. During the first half of the 21 st century, piped water supply was restricted to urban towns, and now that supply system has been introduced into rural areas, water storage practices have changed. Modern transport system (cars and bikes) has also connected the rural areas better, and, finally, solid waste disposal also became a consequence from all this development. These are most cited reasons 
for rural dengue spread. ${ }^{2,3}$ This expanding geographical distribution will pose new challenges in developing the most appropriate strategy for prevention and control.

[J Shaheed Suhrawardy Med Coll 2018; 10(1): 1-2]

DOI: http://dx.doi.org/10.3329/jssmc.v10i1.38894

\section{Prof. Dr. A.H.M. Feroz}

Professor and Head, Department of Medicine, Shaheed Suhrawardy Medical College \& Hospital, Dhaka

\section{References}

1. World Health Organization. Global strategy for dengue prevention and control 2012-2020. Geneva: WHO, 2012. Available from: http://apps.who.

2. Guha Sapir D, Schimmer B. Dengue fever: New paradigms for a changing epidemiology. Emerg Themes Epidemiol 2005;2:1.

3. Rodhain F, Rosen L. Mosquito vectors and dengue virus vector relationships. In: Gubler DJ, Kuno G, editors. Dengue and Dengue Hemorrhagic Fever. New York: CAB International; 1997. p. 4560 .

4. Gubler DJ. The changing epidemiology of yellow fever and dengue, 1900 to 2003: Full circle? Comp Immunol Microbiol Infect Dis 2004;27:319 30
5. Libraty DH, Young PR, Pickering D, Endy TP, Kalayanarooj $\mathrm{S}$, Green S,et al. High circulating levels of the dengue virus nonstructural protein NS1 early in dengue illness correlate with the development of dengue haemorrhagic fever. J Infect Dis 2002;186:1165 8.

6. Nimmanutya S. Dengue haemorrhagic fever: Current issues and future research. Asia Oceanian. J Pediatr Child Health 2002;1:1 22 .

7. Rahman M, Rahman K, Siddque AK, Shoma S, Kamal AH, Ali $\mathrm{KS}$, et al.First outbreak of dengue hemorrhagic fever in Bangladesh. Emerg InfectDis 2002;8:738 40.

8. Gupta E, Dar L, Kapoor G, Broor S. The changing epidemiology of dengue in Delhi, India. Virol J 2006;3:92.19. Kabra SK, Jain Y, Pandey RM, Madhulika, Singhal T, Tripathi $\mathrm{P}$, et al. Dengue haemorrhagic fever in children in the 1996 Delhi epidemic. TransR Soc Trop Med Hyg 1999;93:294 8.

9. Kabra SK, Jain Y, Pandey RM, Madhulika, Singhal T, Tripathi $\mathrm{P}$, et al.Dengue haemorrhagic fever in children in the 1996 Delhi epidemic. Trans R Soc Trop Med Hyg 1999;93:294 8.

10. Shekhar KC, Huat OL. Epidemiology of dengue/dengue hemorrhagicfever in Malaysia: A retrospective epidemiological study 1973-1987.Part I: Dengue hemorrhagic fever (DHF). Asia Pac J Public Health1992 1993;6:15 25.

11. Messer WB, Vitarana UT, Sivananthan K, Elvtigala J, Preethimala LD, Ramesh R, et al. Epidemiology of dengue in Sri Lanka before and after the emergence of epidemic dengue hemorrhagic fever. Am J Trop Med Hyg 2002;66:765 73. 